\title{
Liquefaction Resistance of a Granular Soil Containing Some Admixtures of Fines
}

\author{
Andrzej Sawicki, Jacek Mierczyński, Agata Mikos, Justyna Sławińska \\ Institute of Hydro-Engineering, Polish Academy of Sciences, ul. Kościerska 7, 80-328 Gdańsk, Poland, \\ e-mails: as@ibwpan.gda.pl,mier@ibwpan.gda.pl,amikos@ibwpan.gda.pl,stynaju@ibwpan.gda.pl
}

(Received August 12, 2015; revised October 25, 2015)

\begin{abstract}
The paper deals with the mechanics of sand with some admixtures of fines. The basic question is whether such admixtures are liquefiable or not. Experimental results show that admixtures of fines do not essentially influence the liquefaction susceptibility of granular soils. The original experimental investigations support this conclusion.
\end{abstract}

Key words: liquefaction, admixtures of silt, triaxial investigations

\section{Introduction}

Liquefaction is a phenomenon that transforms an initially solid material into a liquid. Saturated granular soils, such as the seabed, display properties of a solid body, so they can be a good foundation for marine structures. However, under extreme conditions, such as severe storms or seismic excitations, saturated soils behave like a liquid. Structures sink in the liquefied bed, pipelines float out of the ground and coastal landslides take place. These phenomena are described in many publications, see Sumer et al (2007), de Groot et al (2006).

It is commonly accepted that liquefaction occurs only in purely granular soils, such as sands. Liquefaction may be caused by either cyclic or monotonic loadings, see Sawicki and Mierczyński (2006). However, it appears that liquefaction may also take place in saturated granular soils with some admixtures of fines. Yamamuro and Covert (2001) report that liquefaction of a seabed composed of sand and silts took place during an earthquake. The practical and theoretical problem is how to assess the liquefaction potential of a given soil. Geotechnical engineers perform large numbers of laboratory experiments, the results of which are sometimes generalized in the form of empirical formulae, see Idriss and Boulanger (2008). To date, this problem has not been resolved in soil mechanics, as there is a great diversity of opinions. According to Park and Kim (2013), these fines can either increase or decrease the liquefaction resistance of granular soils, which further confuses the issue. Research on this problem 
was initiated long time ago, see Garga and McKay (1984), Guo and Prakash (1999), Ishihara et al (1980), but no convincing results have been obtained, see Xenaki and Athanasopoulos (2003).

The aim of this paper is to study the influence of fines content on the liquefaction potential of the granular seabed, on the basis of the steady-state methodology. The paper deals with the mechanics of sand with some admixtures of fines. The basic question is whether such admixtures are liquefiable or not. Experimental results show that admixtures of fines do not essentially influence the liquefaction susceptibility of granular soils. The original experimental investigations support this conclusion.

\section{The Steady-State Framework}

The steady state (SS) means an unconfined plastic flow of granular soil under constant stresses and volume. The behavior of soil preceding SS depends on its initial state, which may be either contractive or dilative. The initial state of soil is defined by its initial void ratio $e_{0}$ and the initial value of the mean effective stress $p_{0}^{\prime}$, represented as a point in space, see Fig.1.

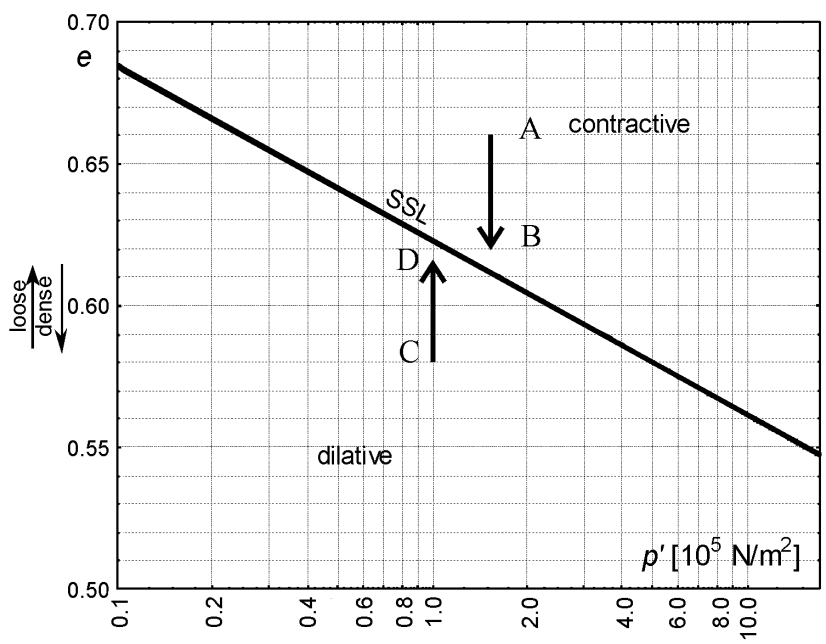

Fig. 1. The steady-state line (SSL) divides regions of initially contractive and dilative states

The point A corresponds to an initially contractive state. It means that a dry soil, or a saturated soil with free drainage allowed, compacts during pure shearing ( $p^{\prime}=$ $p_{0}^{\prime}=$ const) along the path $\mathrm{AB}$. Under undrained conditions, the phenomenon of static liquefaction takes place. The point $\mathrm{C}$ corresponds to an initially dilative state. In this case, during pure shearing, a dry soil compacts first and then dilates. The behavior of an initially dilative soil, sheared under undrained conditions, differs from that of an initially contractive soil, as shown in Fig. 2. It is important to note that liquefaction does not take place in initially dilative soils, but only in contractive ones. 
SSL is usually determined from a series of experiments performed in a triaxial apparatus under both drained and undrained conditions. There are two important objects in the space of effective stresses, as shown in Fig. 2, drawn for axisymmetrical conditions, such as those in the triaxial apparatus. The co-ordinates of the effective stress space are mean effective stress $p^{\prime}$ and deviatoric stress $q$, which are defined as follows:

$$
\begin{gathered}
p^{\prime}=\frac{\sigma_{1}^{\prime}+2 \sigma_{3}^{\prime}}{3}, \\
q=\sigma_{1}^{\prime}-\sigma_{3}^{\prime},
\end{gathered}
$$

where $\sigma_{3}^{\prime}=$ horizontal effective stress, $\sigma_{1}^{\prime}=$ vertical effective stress.
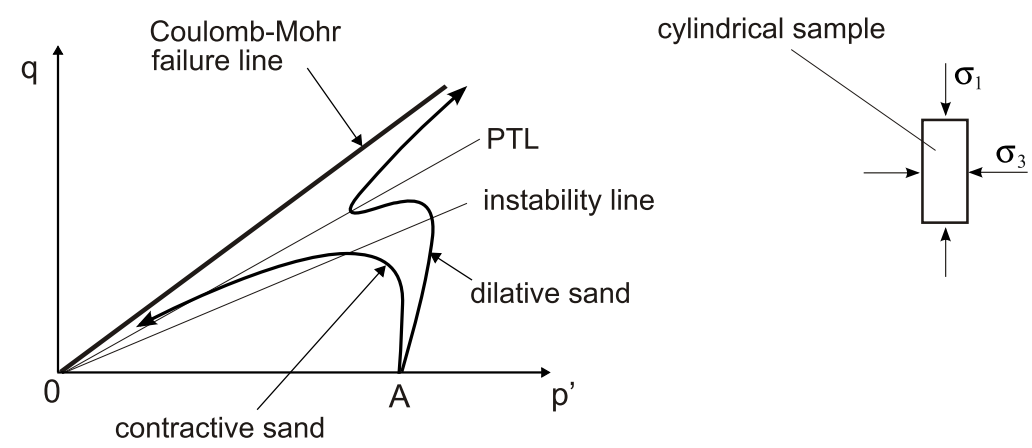

Fig. 2. Effective stress paths followed during undrained shearing of initially contractive and dilative soils

The first important object is the Coulomb-Mohr failure line, corresponding to SS. The other object is the instability line (IL), which corresponds to the maximum shear stress that can be supported by undrained contractive soil during shearing. The phase transformation line (PTL) characterizes the behavior of initially dilative soils. After this line has been reached, their behavior changes from contractive to dilative. Fig. 3 shows steady state lines for the sandy and silty fractions of the soil from the Żelazny Most tailing dam, as well as those corresponding to some mixtures of sand and silt, cf. Fig. 4.

The fundamental conclusion that follows from the above experiments is that fines do influence the liquefaction susceptibility of soils. This means that the area of contractibility increases with the amount of fines, and subsequently the liquefaction potential increases. Lade and Yamamuro (1997) suggest that a mixture of sand and fines is compressible, and its behavior is unstable, Yamamuro and Covert (2001).

\section{Liquefaction Potential/Susceptibility/Resistance}

One of the basic problems in seismic geotechnics is to assess whether a given soil may liquefy or not. A sufficiently general and objective definition of liquefaction poten- 


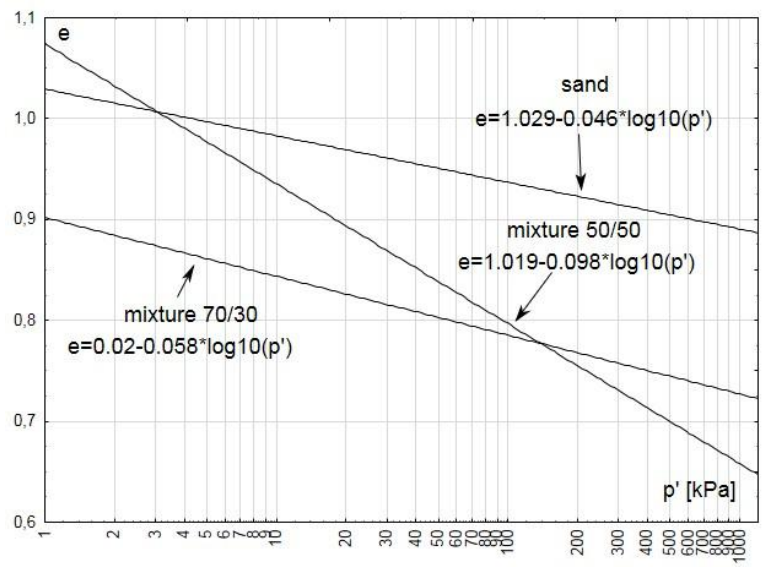

Fig. 3. SSLs for soils containing different amounts of fines

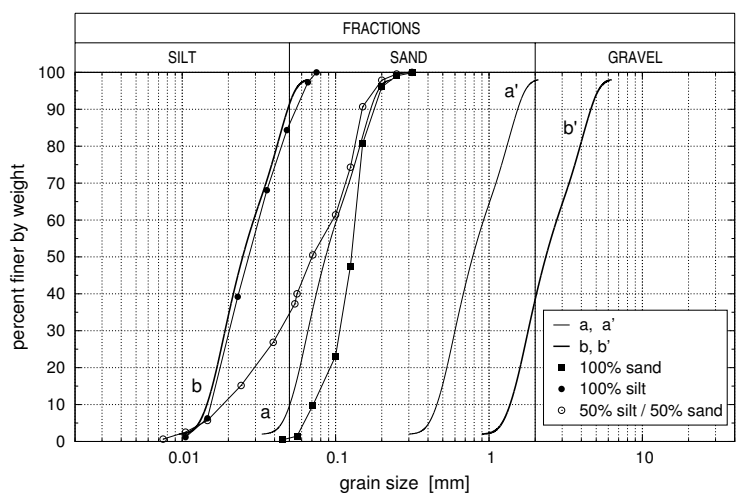

Fig. 4. Tsuchida's curves. The region bounded by the curves a and $a^{\prime}$ is the zone with a high possibility of liquefaction. The zone of possible liquefaction is between the curves $b$ and $b^{\prime}$

tial/susceptibility has not yet been formulated, although some provisional definitions have been proposed. For example: "Resistance to liquefaction is influenced by the initial confining stress, the cyclic shear stress, the number of cycles and void ratio. The cyclic stress ratio to cause 5\% axial strain under 20 load cycles = factor quantifying the liquefaction resistance for given void ratio," Ishihara (1996). He is right that liquefaction depends on the above factors, but he has selected entirely arbitrary numbers, which are not generally applicable.

It was mentioned in the previous section that liquefaction susceptibility strongly depends on the initial state of soil, that is, initially contractive soils can liquefy, whereas initially dilative soils are incapable of liquefaction, cf. Fig. 2. This is one of the most fundamental findings in the mechanics of liquefaction, based on the SS framework. One should also mention an interesting attempt to assess the liquefaction 
susceptibility on the basis of grain distribution curves. Tsuchida (1970) proposes two limiting pairs of grain distribution curves, depicted in Fig. 4, after Ishihara et al (1980). The region bounded by the curves a and $a^{\prime}$ denotes a zone with a high possibility of liquefaction. A zone of possible liquefaction is bounded by the curves $\mathrm{b}$ and $\mathrm{b}^{\prime}$.

Three different grain size distribution curves are also shown in Fig. 4. One of them corresponds to the soil from the Żelazny Most tailing dam (Poland), which is a mixture of sand $(50 \%)$ and silt $(50 \%)$. The other two curves correspond to sandy and silty fractions of this soil. It is interesting to note that the sandy fraction, as well as the mixture of sand and silt, are liquefiable, as the respective grain size distribution curves are located in the region with a high possibility of liquefaction. The curve corresponding to the silty fraction is located in the zone of possible liquefaction.

Granular soils differ from classic solid materials. One of basic differences is that we ask the question of whether a given soil is liquefiable or not. A partial answer is that initially contractive soils can liquefy, whereas initially dilative soils cannot. This may be described as a necessary condition for liquefaction, but it is not a sufficient one.

\section{Static Liquefaction of Mixtures of Sand and Fines}

The experiments were performed on reconstituted soil samples taken from post-flotation deposits collected at the Żelazny Most tailing dam, cf. Figs. 3 and 4, characterized by the coefficient SFR of 16.2 and 1.9.

$$
\mathrm{SFR}=\frac{f>0.075 \mathrm{~mm}}{f<0.075 \mathrm{~mm}}
$$

$f>0.075 \mathrm{~mm}$ - mass of fraction greater than $0.075 \mathrm{~mm}$,

$f<0.075 \mathrm{~mm}-$ mass of fraction smaller than $0.075 \mathrm{~mm}$.

The samples were prepared by the moist tamping method and investigated in a cyclic triaxial apparatus ENEL-HYDRO (Italy), see Świdziński and Mierczyński (2009). The basic experiments dealt with the process of static liquefaction. The experiments were performed under undrained conditions, under constant total stresses. A soil sample was sheared along the "geotechnical" stress path (the vertical total stress increases, and the pressure in the cell is kept constant). Under such conditions, the shear stress $q$ initially increases, and the mean effective stress $p^{\prime}$ decreases because of the generation of excess pore pressure. When the effective stress path reaches the instability line (IL), the shear stress rapidly decreases, and the process of static liquefaction takes place (both $p^{\prime}$ and $q$ rapidly decrease). Fig. 5 shows effective stress paths for a pure sandy fraction. Four different experiments, performed at different initial mean effective stresses, make it possible to determine the instability line $\eta^{\prime}=q / p^{\prime}=0.74$.

Fig. 6 shows similar effective stress paths for a mixture of sand and silt in the proportion of 50\% sand to 50\% silt. IL is similar as in the previous case $\left(\eta^{\prime}=0.69\right)$. A similar process is observed for the 70/30 mixture, see Fig. 7. 


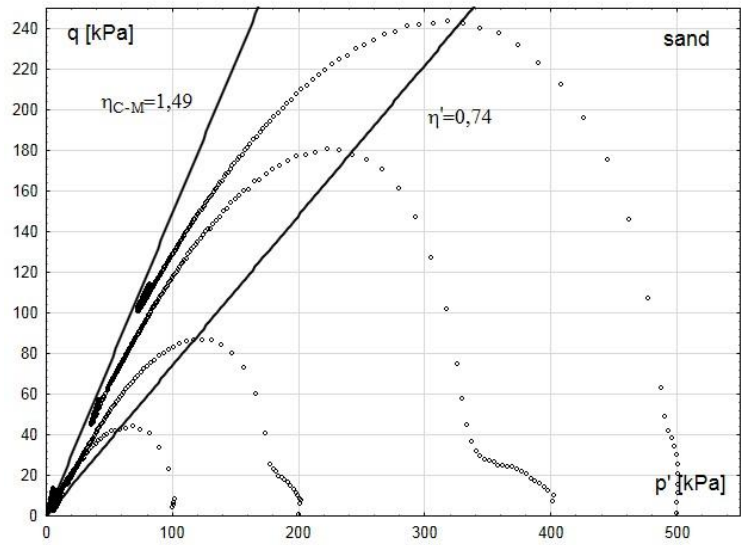

Fig. 5. Static liquefaction of the sandy fraction of the tailing dam soil

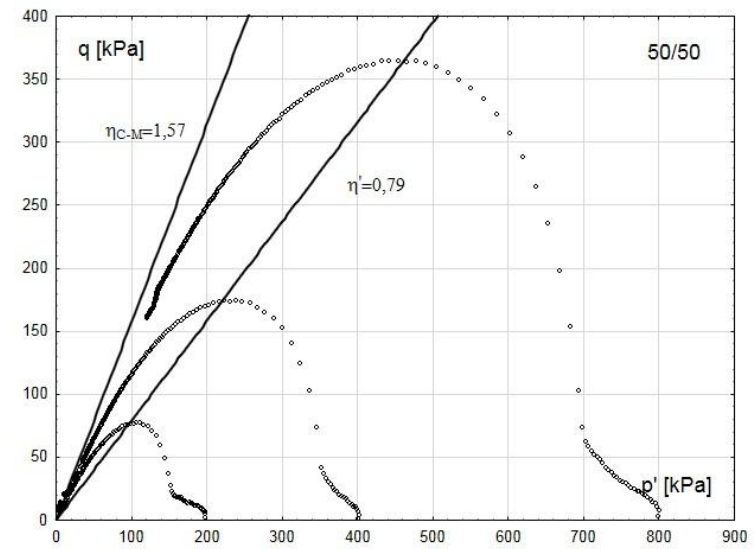

Fig. 6. Static liquefaction of the 50/50 mixture of sand and silt

Fig. 8 shows an interesting behavior of a pure silty fraction. For some initial effective pressures (smaller than $500 \mathrm{kPa}$ ), static liquefaction takes place. For $p^{\prime}=600 \mathrm{kPa}$, the process of cyclic mobility takes place. The instability line is practically the same in all cases considered. Note that in a single experiment static liquefaction does not take place, and the sample displays initially contractive and then dilative behaviour, cf. Fig. 2.

\section{True Triaxial Apparatus}

The true triaxial apparatus has been manufactured by GDS Instruments. The GDS Electro-Mechanical True Triaxial Apparatus, see Fig. 9, is a laboratory system that controls independently normal stresses and strains applied to rectangular paral- 


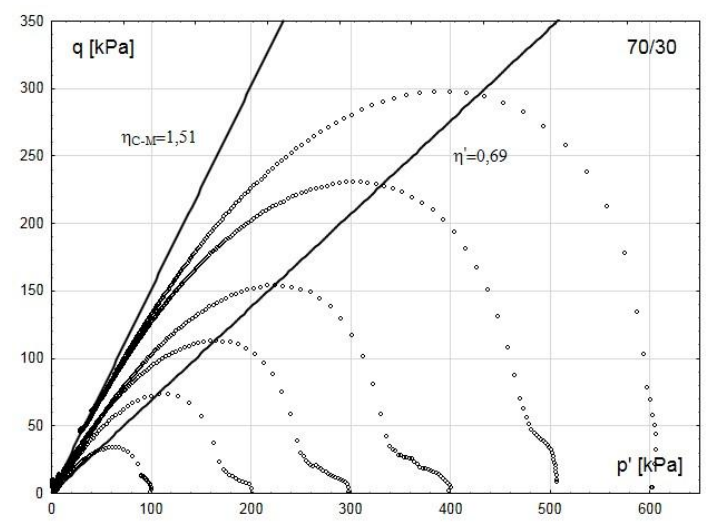

Fig. 7. Static liquefaction of the 70/30 mixture of sand and silt

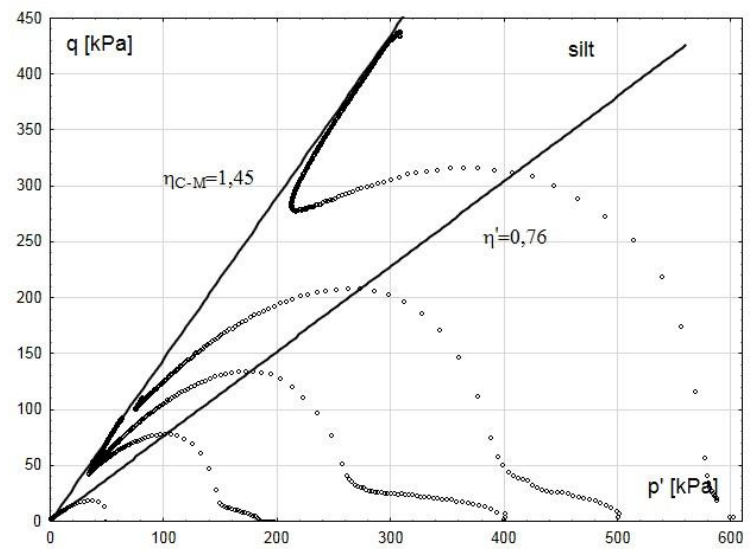

Fig. 8. Static liquefaction of a pure silty fraction

lelepiped soil samples, see Fig. 10. TTA makes it possible to study the behavior of soil under plane strain conditions.

The samples were placed in the triaxial cell, where two plates, shown in Fig. 10, bounded soil deformations in one of horizontal directions in order to achieve plane strain conditions. In a triaxial cell, pressure is controlled. The vertical normal stress is applied via rigid platens, whereas the horizontal normal stress is applied by both rigid platens and a flexible membrane. Load and displacement via the rigid platens are controlled by GDS electro-mechanical actuators. The normal stress is controlled by a GDS pneumatic pressure controller. Back pressure and the recorded volume change of the test specimen are controlled by a GDS pressure/volume controller. The GDS vertical and horizontal electro-mechanical actuators operate dynamically at frequencies up to $5 \mathrm{~Hz}$. The maximum cell pressure is $2000 \mathrm{kPa}$. 


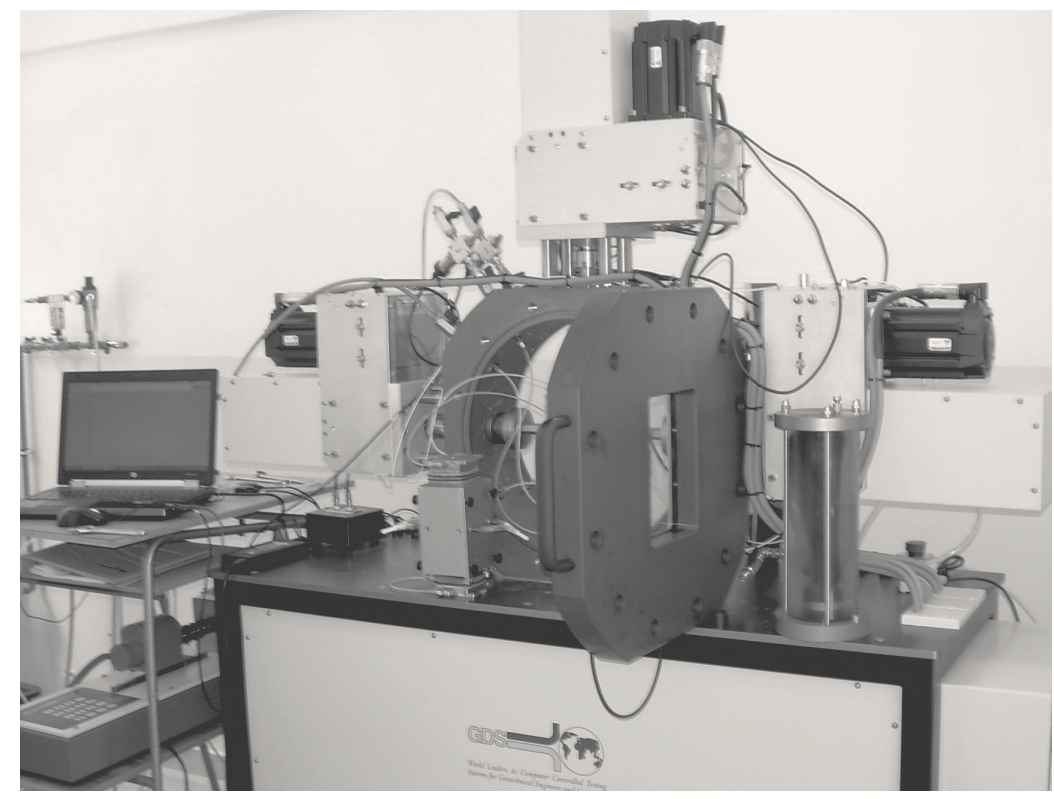

Fig. 9. True triaxial apparatus manufactured by GDS Instruments

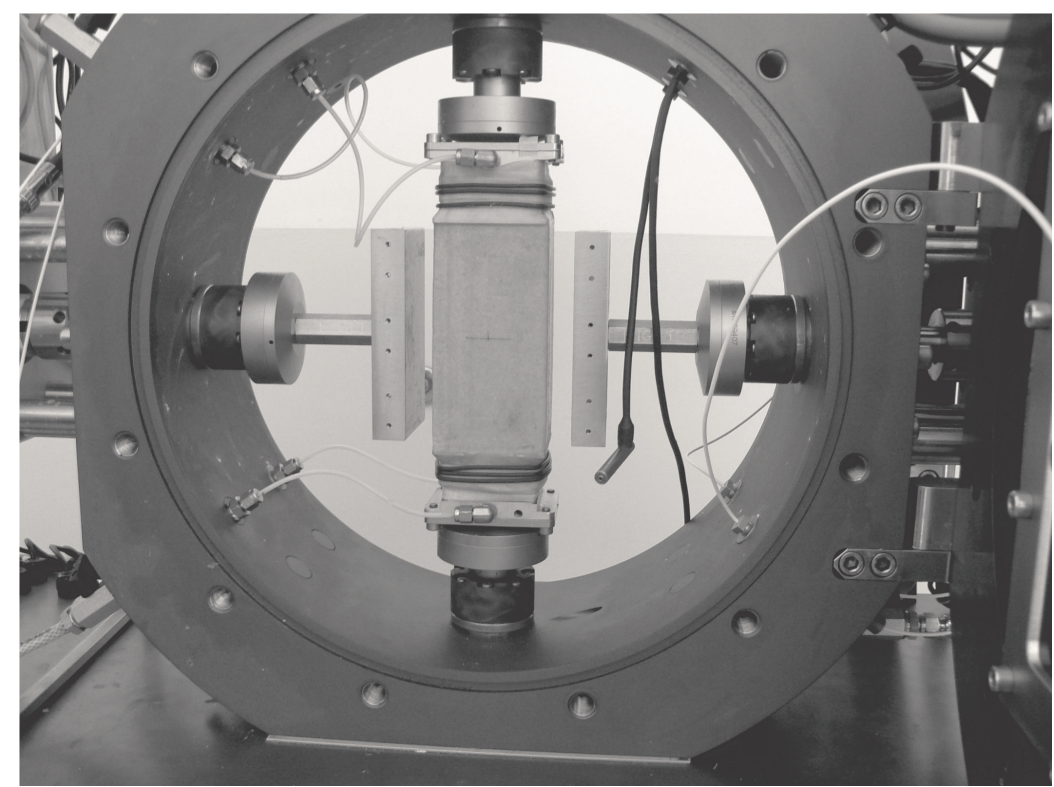

Fig. 10. The chamber of the true triaxial apparatus. The role of the horizontal plates is to prevent soil deformations in one direction in the case of plane strain investigations 


\section{Description of the Plane Strain Experiment}

The experiments were performed on the 50/50 mixture of sand and silt characterized by the following parameters: median size of grains $D_{50}=0.0711 \mathrm{~mm}$, maximum and minimum void ratios $e_{\max }=1.3085$ and $e_{\min }=0.6261$, angle of internal friction $\varphi=$ $38^{\circ}$ for medium dense sand, determined from triaxial experiments. The samples were prepared in a rectangular parallelepiped mould shown in Fig. 11.

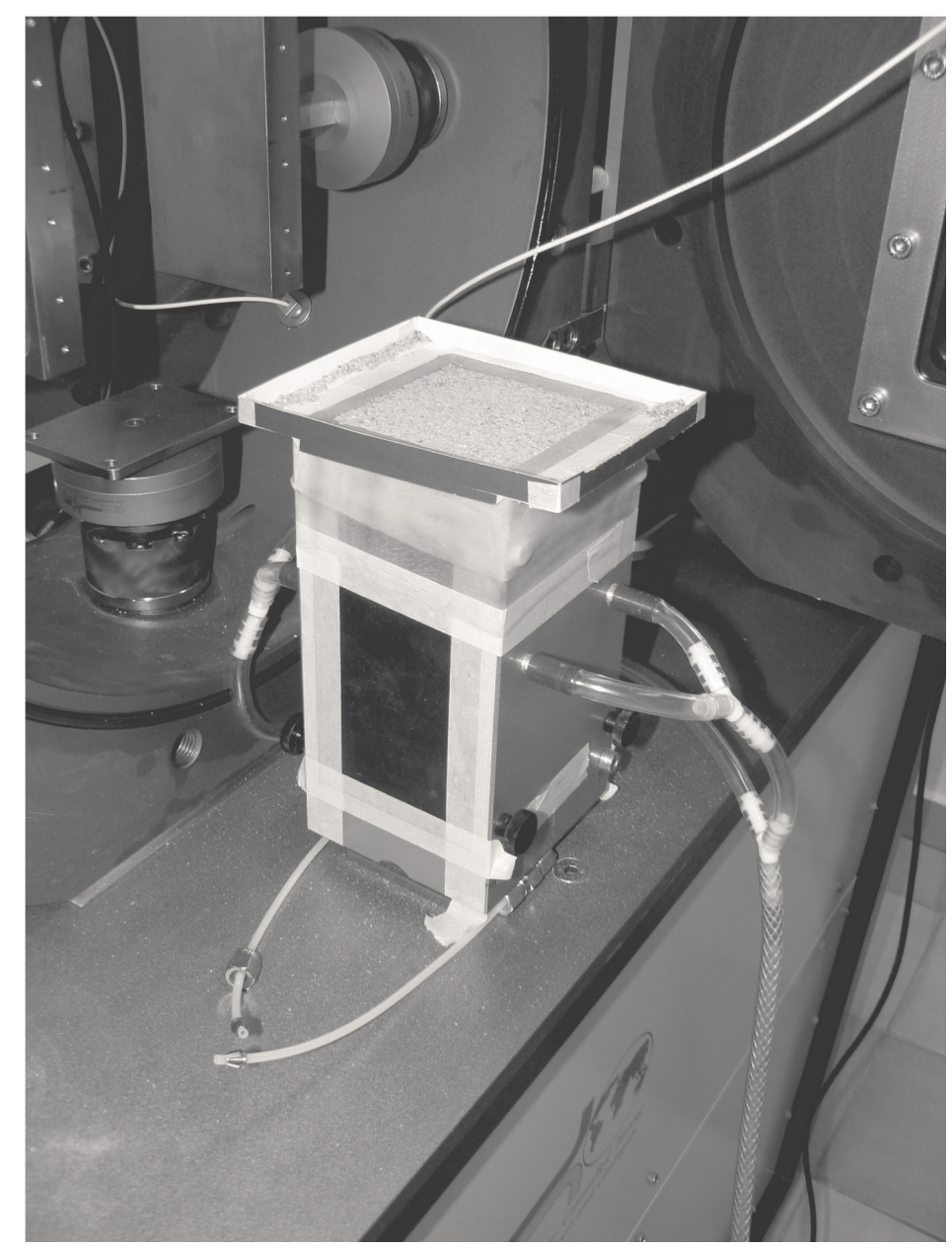

Fig. 11. A soil sample in a metal mould before installation in the triaxial cell

The soil samples were prepared in a flexible membrane, which was placed in the rectangular mould shown in Fig. 11. To fit the rubber membrane to the shape of the mould, suction was applied (about $-30 \mathrm{kPa}$ ) during sample preparation. The dimensions of the samples were as follows: height $=150 \mathrm{~mm}$, width $=75 \mathrm{~mm}$, depth $=$ $72 \mathrm{~mm}$. 
Loose soil samples were prepared by the moist tamping method, and dense soil samples, by air pluvation. The former method made it possible to obtain relatively uniform, very loose samples showing contractive behaviour, whereas the latter produced uniform denser samples of a dilative character.

In the case of moist compacted samples, the mass was divided into eight equal portions. Each portion of sand was given humidity of 3\%. Then each layer of sand was compacted to a desired height. The mass of sand was chosen to obtain a specific density of soil.

\section{Static Liquefaction of Mixtures of Sand and Fines (50/50)}

Fig. 12 shows the experimental result illustrating static liquefaction under plane strain conditions of a sample characterized by the initial void ratio $e_{0}=0.98\left(I_{D}=0.48\right)$. Shearing under undrained conditions started from the following initial conditions: $p^{\prime}=2.2, u=4.4$, both in unit $10^{5} \mathrm{~N} / \mathrm{m}^{2}$, where $u$ is pore pressure.

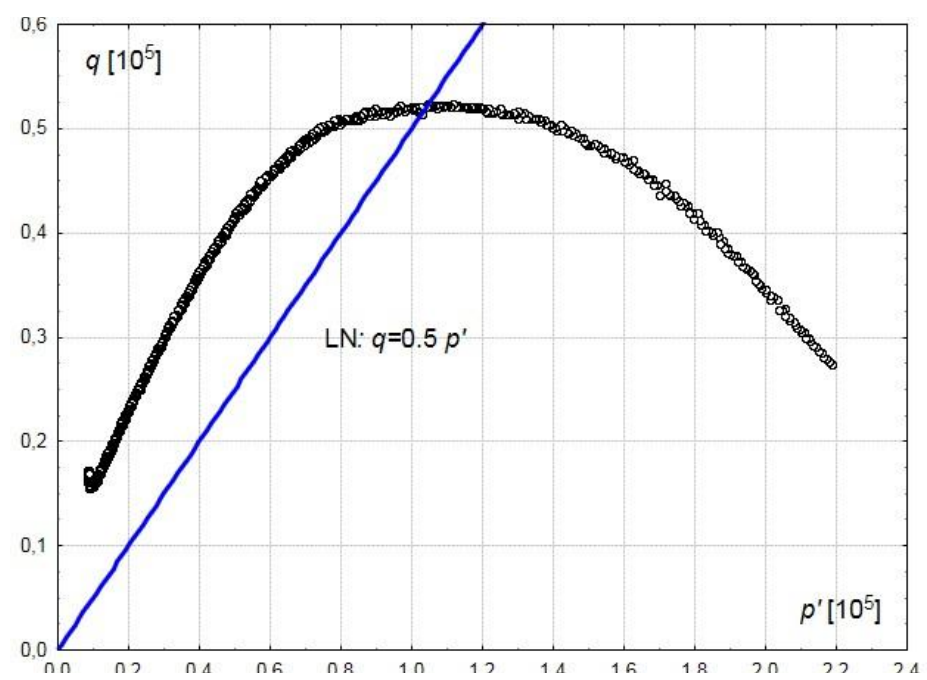

Fig. 12. Static liquefaction of the 50/50 mixture of sand and silt under plane strain conditions

The deviators of strain and effective stress tensors are the following:

$$
\begin{gathered}
\boldsymbol{\varepsilon}^{d e v}=\boldsymbol{\varepsilon}-\frac{1}{2}(\operatorname{tr} \boldsymbol{\varepsilon}) \mathbf{1}=\frac{1}{2}\left[\begin{array}{ll}
\varepsilon_{1}-\varepsilon_{3} & \\
& -\varepsilon_{1}+\varepsilon_{3}
\end{array}\right]=\frac{\sqrt{3}}{2}\left[\begin{array}{ll}
\varepsilon_{q} & \\
& -\varepsilon_{q}
\end{array}\right], \\
\boldsymbol{\sigma}^{\prime d e v}=\boldsymbol{\sigma}^{\prime}-\frac{1}{2}\left(\operatorname{tr} \boldsymbol{\sigma}^{\prime}\right) \mathbf{1}=\frac{1}{2}\left[\begin{array}{ll}
\sigma_{1}^{\prime}-\sigma_{3}^{\prime} & \\
& -\sigma_{1}^{\prime}+\sigma_{3}^{\prime}
\end{array}\right]=\frac{1}{\sqrt{3}}\left[\begin{array}{ll}
q & \\
& -q
\end{array}\right] .
\end{gathered}
$$

The volumetric strain is defined as follows (recall that $\varepsilon_{2}=0$ ):

$$
\varepsilon_{v}=\varepsilon_{1}+\varepsilon_{3}
$$


The mean effective stress is:

$$
p^{\prime}=\frac{1}{2}\left(\sigma_{1}^{\prime}+\sigma_{3}^{\prime}\right)
$$

The other two invariants follow from Eqs. (4) and (5), i.e.

$$
\begin{aligned}
& \varepsilon_{q}=\frac{1}{\sqrt{3}}\left(\varepsilon_{1}-\varepsilon_{3}\right), \\
& q=\frac{\sqrt{3}}{2}\left(\sigma_{1}^{\prime}-\sigma_{3}^{\prime}\right) .
\end{aligned}
$$

Such definitions have been chosen to satisfy the following equation, defining the work $W$ done by the effective stresses on the respective strains:

$$
W=\sigma_{1}^{\prime} \varepsilon_{1}+\sigma_{3}^{\prime} \varepsilon_{3}=\varepsilon_{v} p^{\prime}+\varepsilon_{q} q .
$$

Soil behavior under plane strain conditions, see Fig. 12, is similar to that obtained in classical triaxial tests, see Fig. 6. For plane strain conditions, the stress deviator $q$ first increases, up to $q=0.52$, and then decreases toward zero, see Fig. 12. The instability line is given by the following relation: $\eta=0.5$. The instability line for the 50/50 mixture of sand and silt under plane strain conditions is less inclined than the instability line obtained from the standard triaxial test, because definitions of $p^{\prime}$ and $q$ are different, see (1), (2) and (7), (9).

Soil behaviour under plane strain conditions has been also described by Chu and Wanatowski $(2008,2009)$, who obtained similar results.

\section{Conclusions}

The main results obtained in this paper can be summarized as follows:

- Tsuchida's curves are reliable empirical indicators of the liquefaction susceptibility of soils.

- The steady state approach confirms the reliability of Tsuchida's curves.

- Sands with some admixtures of fines (silt) are liquefiable both in standard triaxial tests and under plane strain conditions.

- Silt fractions are also liquefiable.

- The steady state approach is a good tool to investigate the liquefaction properties of soils.

\section{Acknowledgement}

Research presented in this paper was partly supported by the EU program MERMAID. 


\section{References}

Chu J. and Wanatowski D. (2008) Instability Conditions of Loose Sand in Plane Strain, Journal of Geotechnical and Geoenvironmental Engineering, ASCE, 134 (1), 136-142.

Chu J. and Wanatowski D. (2009) Effect of Loading Mode on Strain Softening and Instability Behaviour of Sand in Plane-Strain Tests, Journal of Geotechnical and Geoenvironmental Engineering, ASCE, 135 (1), 108-120.

Garga V. and McKay L. (1984) Cyclic triaxial strength of mines tailings, Journal of Geotechnical Engineering, ASCE, 110 (8), 1091-1105.

Groot M. B. de, Bolton M. D., Foray P., Meijers P., Palmer A. C., Sandven R., Sawicki A. and Teh T. C. (2006) Physics of liquefaction phenomena around marine structures, Journal of Waterway, Port, Coastal and Ocean Engineering, ASCE, 132 (4), 227-243.

Guo T. and Prakash S. (1999) Liquefaction of silts and silt-clay mixtures, Journal of Geotechnical and Geoenvironmental Engineering, ASCE, 125 (8), 706-710.

Idriss I. M. and Boulanger R. W. (2008) Soil Liquefaction during Earthquakes, Earthquake Engineering Research Institute, MNO-12, Oakland, California.

Ishihara K. (1996) Soil Behaviour in Earthquake Geotechnics, Clarendon Press, Oxford.

Ishihara K., Troncoso J., Kawase Y. and Takahashi Y. (1980b) Cyclic strength characteristics of tailing materials, Soils and Foundations, 20 (4), 127-142.

Lade P. V and Yamamuro J. A. (1997) Effects of nonplastic fines on static liquefaction of sand, Canadian Geotechnical Journal, 34 (6), 918-928.

Park S.-S. and Kim Y.-S. (2013) Liquefaction resistance of sands containing plastic fines with different plasticity, Journal of Geotechnical and Geoenvironmental Engineering, ASCE, 139 (5), 825-830.

Sawicki A. and Mierczyński J. (2006) Developments in modelling liquefaction of granular soils, caused by cyclic loads, Applied Mechanics Reviews, ASME, 59 (2), 91-106.

Sumer B. M., Ansal A., Cetin K. O., Damgaard J., Gunbak A. R., Ottesen Hansen N.-E., Sawicki A., Synolakis C. E., Yalciner A. C., Yuksel Y. and Zen K. (2007) Earthquake-induced liquefaction around marine structures, Journal of Waterway, Port, Coastal and Ocean Engineering, ASCE, 133 (1), 55-82.

Świdziński W. and Mierczyński J. (2009) Experimental investigations of the cyclic mobility of saturated sand (in Polish), Inżynieria Morska i Geotechnika, 4, 271-280.

Tsuchida H. (1970) Prediction and counter measure against the liquefaction in sand deposits (in Japanese), Seminar in the Port and Harbor Research Institute, Ministry of Transport.

Xenaki V. C. and Athanasopoulos G. A. (2003) Liquefaction resistance of sand-silt mixtures: an experimental investigation of the effect of fines, Soil Dynamics and Earthquake Engineering, 23, 183-194.

Yamamuro J. A. and Covert K. M. (2001) Monotonic and cyclic liquefaction of very loose sands with high silt content, Journal of Geotechnical and Geoenvironmental Engineering, ASCE, 127 (4), 314-324. 